\title{
ACTIVITY PATTERNS OF MEN ATTENDING FOR FITNESS ASSESSMENT
}

\author{
P. K. BLAND and P. T. WILLIAMS
}

BUPA Fitness Assessment Unit, BUPA Medical Centre, London N1 9TA

\section{ABSTRACT}

This paper describes some fitness and health characteristics of 499 British men in relation to their age and activity levels. The men attended a fitness assessment unit on a voluntary basis and their ages ranged from 20 to 69 years (43.8 $\pm 9.1 \mathrm{yr}$, mean \pm SD).

All subjects underwent a complete medical examination prior to carrying out a standardised graded walking or running test on a treadmill. During the test expired air collections were made and maximal oxygen uptake $\left(\mathrm{VO}_{2}\right.$ max $)$ was predicted from the oxygen uptake and heart rate measurements. All subjects were required to exercise up to $90-95 \%$ of their predicted maximum heart rate.

Activity levels were assessed from a number of questions put to the patient by the doctor about the amount and type of exercise taken. Only $22 \%$ of the sample performed the minimum amount of exercise required to maintain a good functional capacity as recommended by the American College of Sports Medicine. Thirty-nine per cent were sedentary.

The activity patterns of the older subjects differed from those of the younger subjects. The older age groups contained more sedentary individuals and fewer moderately active individuals (i.e. those taking exercise only once or twice a week). However the numbers taking regular exercise three or more times a week did not vary from one age group to the next.

The mean $\mathrm{VO}_{2}$ max for the sample was $41.9 \pm 9.0 \mathrm{ml} \mathrm{kg}^{-1} \mathrm{~min}^{-1}$ and the mean body fat percentage $21.2 \pm 5.6 \%$. The more active groups had higher $\mathrm{VO}_{2}$ max values and lower body fat, body weight and blood pressure values when compared with the less active groups. These differences were independent of age. These observations support the increasing evidence that exercise has a beneficial effect on health.

Key words: Physical activity, Maximal oxygen uptake, Body fat percentage, Body weight, Resting blood pressure, Resting pulse rate

\section{INTRODUCTION}

Physical activity patterns, fitness levels and some health related parameters have been examined in 499 men attending a Fitness Assessment Unit between 1983-87.

The influence of physical activity and fitness on health is well documented (Morris et al, 1973), particularly in relation to ischaemic heart disease (Paffenbarger et al, 1978). However, few studies have included an objective assessment of fitness. This study includes such a measure by predicting the commonly accepted index of cardiorespiratory fitness (maximum oxygen uptake). A number of population studies investigating fitness and activity levels have been carried out in other countries (Canadian Fitness Survey, 1983; Åstrand, I., 1960) but no such population study has been performed in Britain. Over 4,000 British men have been tested at this unit and the aim of this paper is to provide a preliminary report of a sample of this population before describing the total group at a later date.

\section{METHOD}

\section{General description of the sample}

The sample of 499 men was selected randomly from over 4,000 men attending the unit on a voluntary basis between 1983-87. The majority of this sample (mean age \pm SD $43.8 \pm$ 9.1 years) were married with a family $(79 \%)$ and grouped in social classes A and B (87\%). Sixty-nine per cent were aged between $30-49$ years and $90.5 \%$ between $30-59$ years. Seventy-seven per cent lived within 50 miles of London and $88 \%$ within 100 miles of London (Hodgson, 1986). The

\section{Address for correspondence:}

Miss P. K. Bland, MPhil, BSc

Fitness Assessment Unit

BUPA Medical Centre

Webb House

210 Pentonville Road

London N1 9TA majority were non-smokers and consumed less than 4 units of alcohol a day (Hodgson, 1986). This description demonstrates that the sample is not representative of the British population at large.

\section{Medical examination and supervision}

All individuals underwent a full medical examination prior to physiological testing. The medical examination included measurement of blood pressure, measurement of height and weight, a blood test, 12-lead electrocardiogram, the taking of a medical history and an examination by a doctor. Individuals who were considered medically unsuitable for exercise testing were not included in the sample. However, these numbered only a few (5 patients in 4,000$)$. Patients on beta-blocker or digitalis therapy were excluded from the study $(100$ in 4,000).

\section{Activity evaluation}

The activity levels of the participants were assessed from their responses to a number of standard questions put to them by the doctor. The questions covered the type, intensity, frequency and duration of the exercise taken. The subjects were then given an activity rating on a scale of 1-7 (Fig. 1) with activity ' 1 ' being the most sedentary and activity ' 7 ' being the most active. To qualify for a given activity rating the individual must have performed the exercise consistent with that rating for a minimum of 3 months immediately prior to testing. Activity ratings ' 5 ' and ' 6 ' were established as the minimum and maximum desired levels for developing and maintaining cardiovascular fitness (American College of Sports Medicine, 1986). The remaining activity ratings were those that best described the population under study.

\section{Anthropometric assessment}

All subjects were weighed on a Salter balance (Marsden) and their standing height was measured using a stadiometer. Body fat was assessed from the sum of four 
Activity Classification

\begin{tabular}{|c|c|c|}
\hline Rating & Description & Activity Level \\
\hline 1 & sedentary & $\begin{array}{l}\text { Individuals who admit to taking no exercise of any } \\
\text { kind, including at work ( } 0 \mathrm{hrs} / \mathrm{wk}) \text {. }\end{array}$ \\
\hline 2 & $\begin{array}{l}\text { casual } \\
\text { exerciser }\end{array}$ & $\begin{array}{l}\text { This includes the irregular, casual exerciser, e.g. } \\
\text { gardener, dog walker (low intensity, 0-3 hrs/wk). }\end{array}$ \\
\hline 3 & $\begin{array}{l}\text { moderately } \\
\text { active }\end{array}$ & $\begin{array}{l}\text { Regular 1-2 times a week exerciser (medium to } \\
\text { hard, } 1-3 \mathrm{hrs} / \mathrm{wk} \text { ). }\end{array}$ \\
\hline 4 & active & $\begin{array}{l}\text { Individuals who exercise regularly 3-6 times a week } \\
\text { but who do not take any endurance exercise e.g. } \\
\text { badminton 3-4 times/week (Medium/hard, } \\
\text { 3-4 hrs/wk). }\end{array}$ \\
\hline 5 & $\begin{array}{l}\text { medical } \\
\text { minimum }\end{array}$ & $\begin{array}{l}\text { Individuals who perform the minimum amount of } \\
\text { exercise required to develop and maintain cardio- } \\
\text { vascular fitness (i.e. endurance exercise } 3-4 \\
\text { times/week at } 50-85 \% \mathrm{VO}_{2} \text { max, } 1.5-2 \mathrm{hrs} / \mathrm{wk} \text { ). }\end{array}$ \\
\hline 6 & $\begin{array}{l}\text { medical } \\
\text { maximum }\end{array}$ & $\begin{array}{l}\text { Individuals who exercise in excess of ' } 5 \text { ' i.e. 5-6 } \\
\text { times a week for } 20-30 \mathrm{~min} \text { at } 50-85 \% \mathrm{VO}_{2} \max \\
(2.5-3 \mathrm{hrs} / \mathrm{wk}) \text {. }\end{array}$ \\
\hline 7 & $\begin{array}{l}\text { endurance } \\
\text { trained }\end{array}$ & $\begin{array}{l}\text { Individuals who exercise in excess of ' } 6 \text { ' e.g. } \\
30 \text { miles/week + ( } 3 \text { hrs }+/ w k) \text {. }\end{array}$ \\
\hline
\end{tabular}

Activity '1' '2' = "mainly sedentary"

Activity ' 3 ' = "moderately active"

Activity '4' = "active"

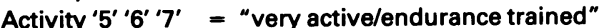

Fig. 1: Activity classification.

skinfolds (bicep, tricep, subscapular and suprailiac) which were determined using Harpenden skinfold calipers. The sum of the four skinfold measurements was used to provide an estimate of the percentage body fat using the formula of Durnin and Womersley (1974).

\section{Exercise test}

All subjects were tested on a heavy duty treadmill (Woodway, speed $0-11 \mathrm{mph}$, gradient $0-20 \%$ ). The individuals undertook either a walking or a running test depending upon their age, health status and current activity level. Broadly speaking individuals over 50 years and/or individuals with an activity rating of 1-4 performed the walking test. Subjects with an activity rating of 5-7 and/or subjects under 25 in the main performed the running test.

All individuals were familiarised with treadmill walking and/or running as well as the mouthpiece and nose-clip required for the collection of expired air. The majority of subjects were comfortable with the equipment after 5 minutes. All treadmill familiarisation was carried out at an exercise intensity which was less than that demanded at the first stage of the exercise test. Those subjects who could not tolerate either the treadmill or the mouthpiece were excluded from the study $(6$ in 4,000$)$.

\section{Walking test at 1.57 m.s -1}

The test protocol used was that used by Williams and Hamley (1983), a modification of the Bruce protocol (1969). The treadmill speed was set at a constant rate of $1.57 \mathrm{m.s}$ and the gradient increased every third minute from an initial level of $5 \%$ to a maximum level of $17.5 \%$. The intermediate gradients were $10 \%, 12.5 \%$ and $15 \%$, making a total of 5 stages and 15 minutes. A time of three minutes at each gradient was selected as experience suggests this is the minimum time required to reach steady state.

\section{Running test at 3.13 m.s ${ }^{-1}$}

The running test used was that designed by Taylor et al (1955). The subjects ran at a constant speed of $3.13 \mathrm{~m} . \mathrm{s}^{-1}$ with the gradient of the treadmill being increased progressively from $3.5 \%$ by $2.5 \%$ every 3 minutes.

In both tests the individuals exercised up to at least $90 \%$ of their predicted maximum heart rate [ 220 - (age $\times 0.65$ ) and $210-$ (age $\times 0.65$ ), for sedentary and trained individuals respectively (American Heart Association, 1972)] or until they reached subjective exhaustion. A subject allocated to the walking test who did not achieve his $90 \%$ predicted heart rate also performed the running test. All tests were supervised by a doctor, an exercise physiologist and a nurse and resuscitation equipment was available at all times.

\section{Measurements made during the exercise test}

Heart rate was monitored continuously throughout the exercise test from chest electrodes on a Marquette CASE 11 oscilloscope and recorded at the end of each three minute block. Recovery heart rates were recorded routinely at one and three minutes post-exercise. Gas analysis measurements were made in the final minute of each three minute block using the Pulmonary Work Station 9000 (Gould Medical). A low resistance respiratory valve was attached to the mouthpiece for collection of expired air (Jakeman and Davies, 1979). Blood pressure measurements were made every third minute using the Critikon Exercise Monitor 1165. Predicted maximum oxygen uptake $\left(\mathrm{VO}_{2} \mathrm{max}\right.$ ml. $\left.\mathrm{kg}^{-1} \mathrm{~min}^{-1}\right)$ was determined by plotting the heart rate against the oxygen uptake, fitting a straight line into the plots and extrapolating to the predicted maximum heart rate (Maritz et al, 1961).

\section{Statistical analysis}

A t-test for independent samples was used to test for differences between the various age groups and between the various activity groups. A chi-square test was used to test for the independence of activity in relation to age. All results are presented as the mean \pm SD.

\section{RESULTS}

The results of 499 British men aged 20-69 years attending a Fitness Assessment Unit in London between 1983-87 have been described and analysed.

\section{Activity levels of the group}

The majority of the group were active at least once a week $(61 \%)$. Thirty-nine per cent were "mainly sedentary" i.e. either totally inactive or performing light activity such as gardening on an irregular basis. Twenty-one per cent were "moderately active" i.e. they exercised on a regular basis 12 times a week and $39 \%$ exercised regularly three or more times a week ("active" to "very active"). Only $22 \%$ of the total group followed a definite endurance exercise programme. The activity pattern of the group is summarised in Fig. 2.

Fig. 3 illustrates the variation in activity patterns with age. The percentage contribution of activity categories ' 1 ' and ' 2 ' (mainly sedentary) to the total activity pattern increased from $23 \%$ in the youngest age group to $43 \%$ in the oldest age group. The "moderately active" group (activity rating ' 3 ') decreased in size with age from $31 \%$ in the youngest age group to $11 \%$ in the oldest age group. The "active" and "very active" groups (activity ratings ' 4 ', ' 5 ', ' 6 ' and ' 7 ') however showed very little difference in their size when expressed as a percentage from one age group to the next. 


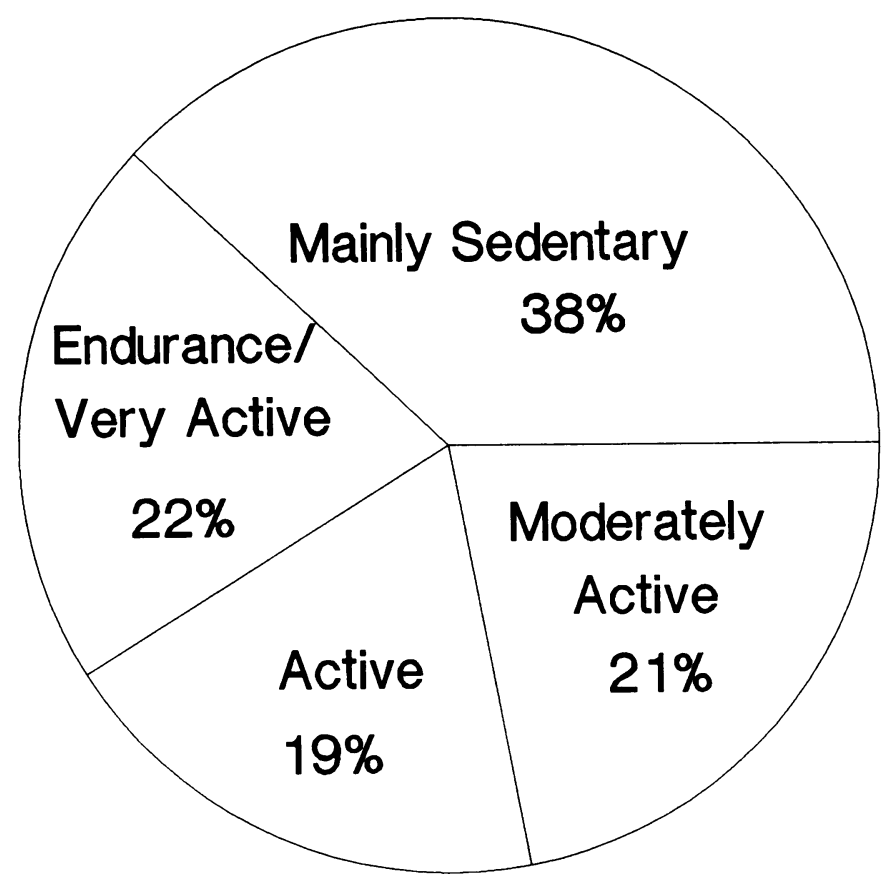

Fig. 2: Activity levels in British men attending a Fitness Assessment Unit.
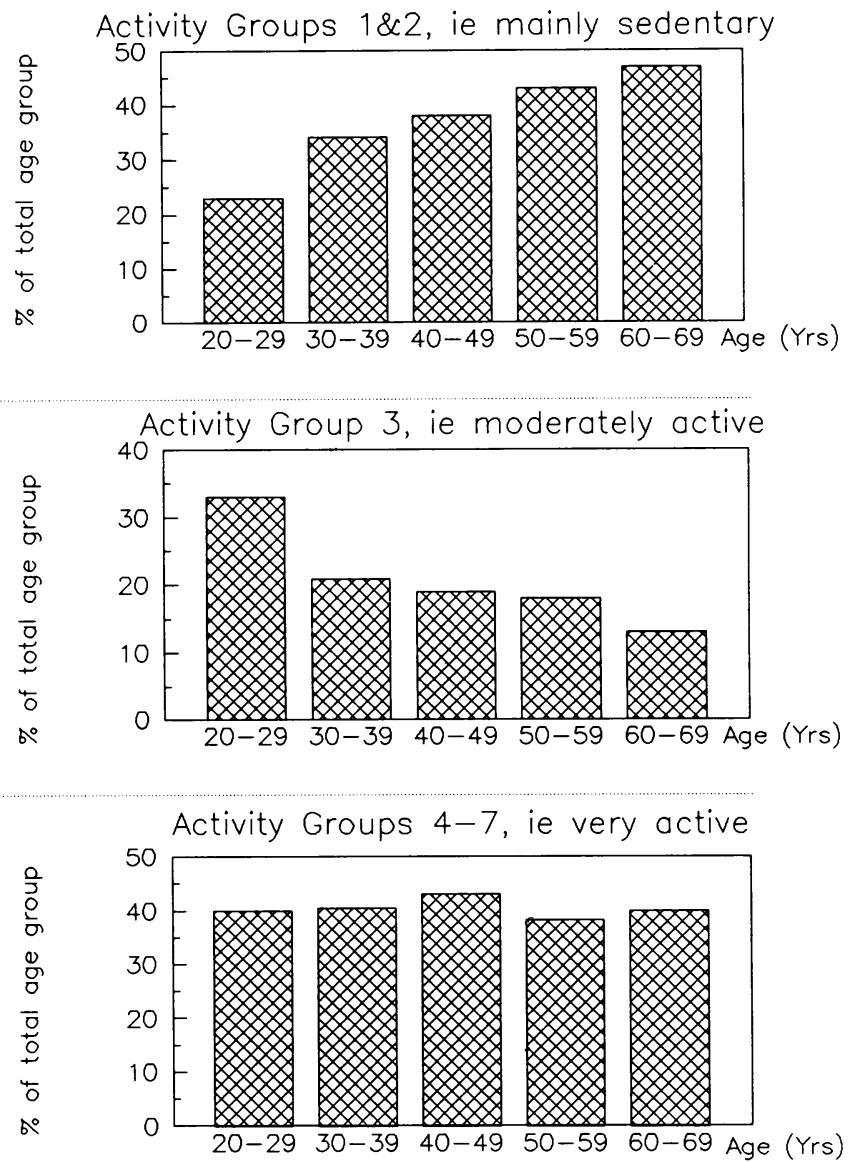

Fig. 3: Activity levels in relation to age.

\section{Anthropometric characteristics of the subjects}

The mean heights and weights for the different age groups are presented in Table I. The average heights of the older age groups were significantly lower than those of the younger age groups. The 60-69-year-old group were significantly shorter than all of the other age categories.
TABLE I

Height, weight and body fat percentage in 499 British men aged 20-69 years attending a fitness assessment unit

\begin{tabular}{lcrrrrr}
\hline & & \multicolumn{5}{c}{ Age Group (yrs) } \\
Variable & & $20-29$ & $30-39$ & $40-49$ & $50-59$ & $60-69$ \\
\hline Height (cms) & $\bar{X}$ & 176.5 & 178.1 & 178.0 & 176.6 & 174.1 \\
& SD & 5.6 & 6.7 & 6.7 & 6.7 & 8.7 \\
Weight (kg) & $\bar{X}$ & 73.9 & 78.8 & 79.5 & 78.8 & 75.1 \\
& SD & 11.4 & 11.1 & 10.1 & 11.4 & 7.6 \\
Body Fat (\%) & $\bar{X}$ & 16.5 & 20.5 & 23.0 & 25.0 & 23.5 \\
& SD & 5.5 & 3.8 & 4.3 & 5.2 & 7.0 \\
& $\mathrm{n}$ & 26 & 146 & 198 & 110 & 19 \\
\hline & & & & & &
\end{tabular}

Body fat percentage was significantly greater in the older age groups $(16.5 \pm 5.5 \%$ in the $20-29$ age group compared with $25.3 \pm 7.0 \%$ in the $60-69$ age group, $P<0.001$, Table I). The differences from one age group to the next were all statistically significant with the exception of the two oldest age groups.

Body weight and body fat percentage both decreased with increasing activity levels (Table II, Fig. 4). The mean body weight was higher in the totally sedentary group (activity rating ' 1 ') $(82.0 \pm 12.9 \mathrm{~kg})$ than in the most active group (activity ' 7 ', $P<0.001)(73.8 \pm 12.5 \mathrm{~kg})$. The sedentary group were significantly heavier than all of the other activity groups.

\section{TABLE \|}

Height, weight and percentage body fat in relation to activity in 499 British men attending a fitness assessment unit

\begin{tabular}{lcrrrrrrr}
\hline & & \multicolumn{7}{c}{ Activity Groups } \\
Variable & & \multicolumn{1}{c}{1} & \multicolumn{1}{c}{2} & \multicolumn{1}{c}{3} & \multicolumn{1}{c}{4} & 5 & 6 & 7 \\
& & & & & & & & \\
\hline Age & $\bar{X}$ & 46.2 & 45.0 & 42.6 & 44.9 & 44.2 & 45.9 & 41.0 \\
(yrs) & SD & 9.2 & 9.8 & 9.3 & 8.7 & 8.6 & 9.5 & 10.0 \\
Height & $\bar{X}$ & 176.2 & 177.8 & 177.5 & 178.3 & 177.7 & 176.3 & 178.2 \\
(cms) & $\mathrm{D}$ & 8.1 & 5.9 & 6.1 & 7.1 & 6.7 & 5.5 & 4.6 \\
Weight & $\bar{X}$ & 82.0 & 79.2 & 79.1 & 77.9 & 76.3 & 74.8 & 73.8 \\
(kg) & SD & 12.9 & 11.2 & 10.5 & 8.2 & 8.5 & 8.0 & 12.5 \\
Body Fat & $\bar{X}$ & 24.6 & 23.4 & 22.5 & 22.0 & 20.5 & 21.0 & 17.7 \\
(\%) & SD & 4.9 & 5.1 & 4.9 & 5.0 & 3.6 & 4.3 & 5.0 \\
& $\mathrm{n}$ & 100 & 89 & 105 & 95 & 55 & 30 & 25 \\
\hline & & & & & & & &
\end{tabular}

Body fat percentage was higher in the sedentary group $(24.6 \pm 4.9 \%)$ than in the most active group $(17.7 \pm 5.0 \%$, $P<0.001)$. The sedentary group had significantly more body fat than each of the other six activity groups with the exception of activity group '2' (Table II, Fig. 4).

\section{Cardiorespiratory analysis}

The average resting heart rates and arterial blood pressures for the different age groups are presented in Table III. Blood pressure was higher in the older age groups than in the younger age groups but the mean heart rates did not vary from one age group to the next (Table III). The influence of activity levels on these parameters is presented in Table IV and Fig. 5. The mean values for the resting systolic and diastolic blood pressures were $129 \pm 18 \mathrm{mmHg}$ and $81 \pm 12 \mathrm{mmHg}$ respectively in the sedentary group and $121 \pm 12$ and $71 \pm 15 \mathrm{mmHg}$ in the most active group 
$(P<0.001)$. The mean resting heart rate was $71 \pm 11$ beat. $\mathrm{min}^{-1}$ for the most sedentary and $61 \pm 9$ beat. min $^{-1}$ for the most active group $(P<0.001)$.
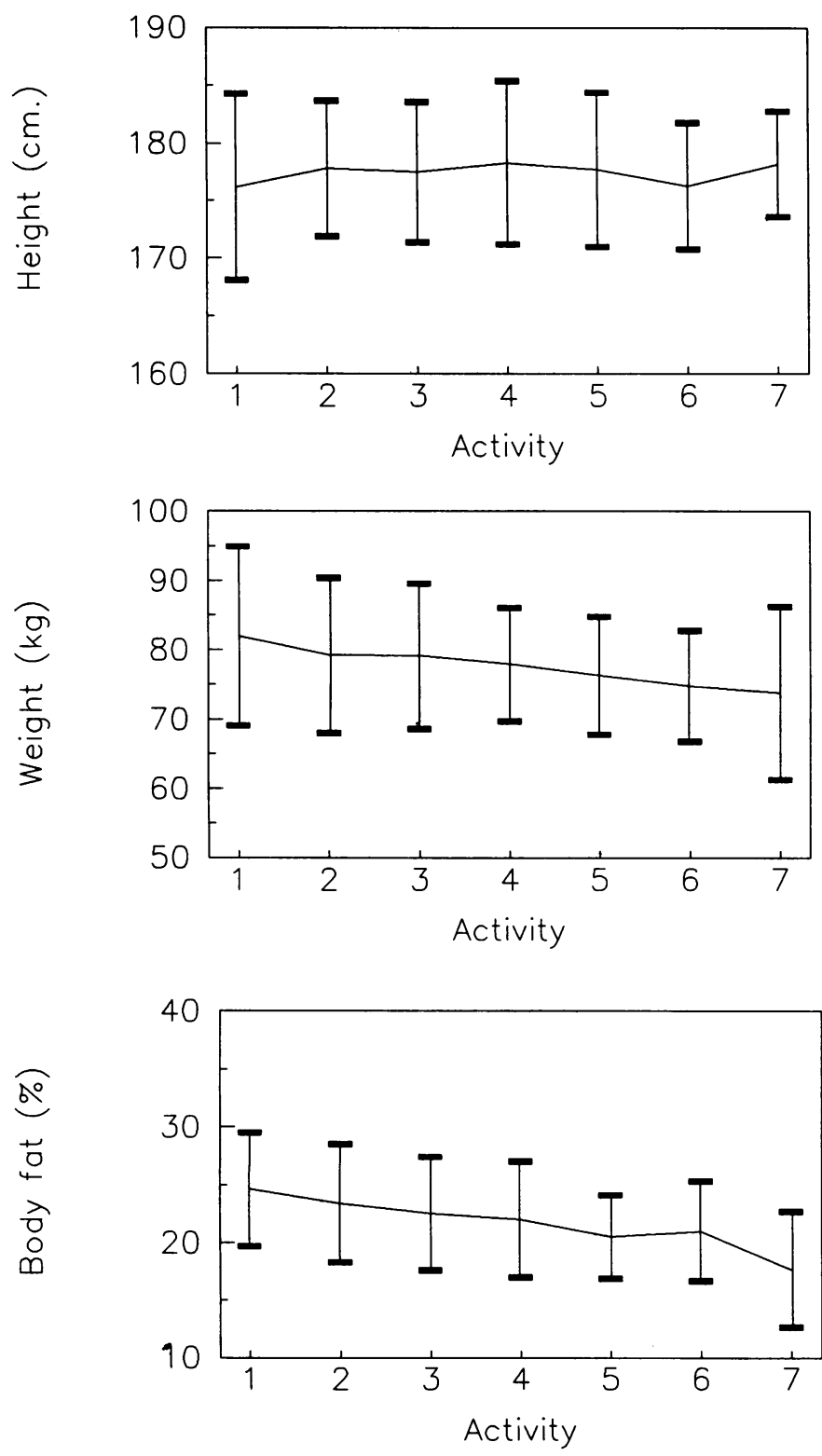

Fig. 4: Height, weight and body fat percentage in relation to activity (mean \pm SD).

\section{TABLE III}

Resting heart rate, resting blood pressure and predicted maximum oxygen uptake for 499 British men aged 20-69 years attending a fitness assessment unit

\begin{tabular}{|c|c|c|c|c|c|c|}
\hline \multirow[b]{2}{*}{ Variable } & & \multicolumn{5}{|c|}{ Age Group (yrs) } \\
\hline & & $20-29$ & $30-39$ & $40-49$ & $50-59$ & $60-69$ \\
\hline $\begin{array}{l}\text { Heart rate } \\
\text { (b.min-1) }\end{array}$ & $\begin{array}{l}\bar{X} \\
\text { SD }\end{array}$ & $\begin{array}{l}72 \\
13\end{array}$ & $\begin{array}{l}67 \\
11\end{array}$ & $\begin{array}{l}66 \\
10\end{array}$ & $\begin{array}{l}67 \\
10\end{array}$ & $\begin{array}{r}66 \\
8\end{array}$ \\
\hline $\begin{array}{l}\text { Systolic BP } \\
\text { (mmHg) }\end{array}$ & $\begin{array}{c}\bar{X} \\
\text { SD }\end{array}$ & $\begin{array}{r}126 \\
17\end{array}$ & $\begin{array}{r}125 \\
15\end{array}$ & $\begin{array}{r}125 \\
13\end{array}$ & $\begin{array}{r}130 \\
18\end{array}$ & $\begin{array}{r}136 \\
10\end{array}$ \\
\hline $\begin{array}{l}\text { Diastolic BP } \\
\text { (mmHg) }\end{array}$ & $\begin{array}{c}\bar{X} \\
\text { SD }\end{array}$ & $\begin{array}{r}75 \\
9\end{array}$ & $\begin{array}{l}76 \\
10\end{array}$ & $\begin{array}{l}78 \\
10\end{array}$ & $\begin{array}{l}80 \\
13\end{array}$ & $\begin{array}{r}84 \\
9\end{array}$ \\
\hline $\begin{array}{l}\mathrm{VO}_{2} \max \\
\left(\mathrm{ml} \mathrm{kg}^{-1} \mathrm{~min}^{-1}\right)\end{array}$ & $\begin{array}{c}\bar{X} \\
\text { SD }\end{array}$ & $\begin{array}{l}47.0 \\
10.5\end{array}$ & $\begin{array}{r}42.7 \\
8.3\end{array}$ & $\begin{array}{r}42.8 \\
9.0\end{array}$ & $\begin{array}{r}39.1 \\
8.4\end{array}$ & $\begin{array}{r}35.8 \\
7.0\end{array}$ \\
\hline & $n$ & 26 & 146 & 198 & 110 & 19 \\
\hline
\end{tabular}
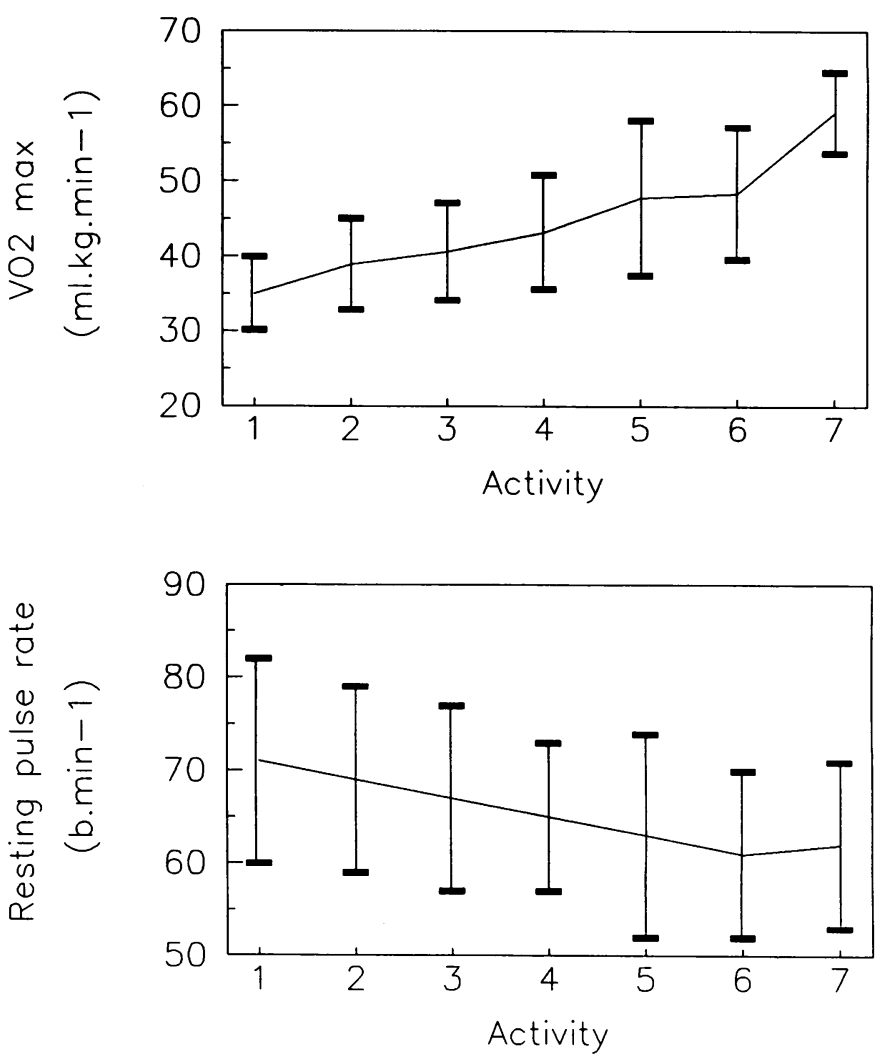

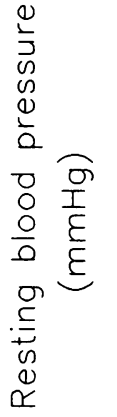

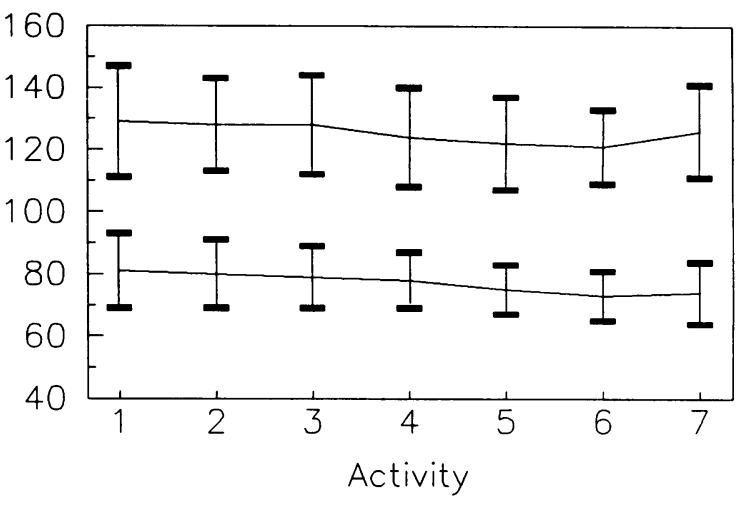

Fig. 5: Maximum oxygen uptake, resting blood pressure and resting pulse rate in relation to activity (mean $\pm S D$ ).

The mean predicted maximal oxygen uptake value for the group was $43.8 \pm 8.0 \mathrm{ml} . \mathrm{kg}^{-1} \mathrm{~min}^{-1}$. The average values for the older age groups were lower than those of the younger age groups although there was no difference between the 30-39 and the 40-49-year-old age groups (Table III). Predicted maximal oxygen uptake was higher in the higher activity groups (Table IV, Fig. 5), i.e. $35.8 \pm 7.0$ $\mathrm{ml} . \mathrm{kg}^{-1} \mathrm{~min}^{-1}$ for the completely sedentary group and $\mathbf{5 9 . 2}$ $\pm 5.4 \mathrm{ml}^{.} \mathrm{kg}^{-1} \mathrm{~min}^{-1}$ in the most active group.

A chi-square test was used to check for the independence of activity in relation to age. This was not significant indicating that the changes reported above from one activity group to the next were independent of age.

\section{DISCUSSION}

\section{Activity patterns}

According to the ACSM (1986), the minimum amount of activity required to produce and maintain a good functional capacity is endurance exercise three times a week at 50 $85 \% \mathrm{VO}_{2}$ max for $15-30$ minutes. However, only $22 \%$ of the sample performed this minimum amount and therefore the 
TABLE IV

Resting heart rate, blood pressure and predicted maximum oxygen uptake in relation to activity in $\mathbf{4 9 9}$ British men attending a fitness assessment unit

\begin{tabular}{|c|c|c|c|c|c|c|c|c|}
\hline \multirow[b]{2}{*}{ Variable } & \multicolumn{8}{|c|}{ Activity Groups } \\
\hline & & 1 & 2 & 3 & 4 & 5 & 6 & 7 \\
\hline Heart rate & $\bar{x}$ & 71 & 69 & 67 & 65 & 64 & 61 & 62 \\
\hline (b. $\left.\min ^{-1}\right)$ & SD & 11 & 10 & 10 & 8 & 13 & 9 & 9 \\
\hline Systolic BP & $\bar{x}$ & 129 & 128 & 128 & 124 & 122 & 121 & 126 \\
\hline$(\mathrm{mmHg})$ & SD & 18 & 15 & 16 & 16 & 15 & 12 & 15 \\
\hline Diastolic BP & $\bar{x}$ & 81 & 80 & 79 & 78 & 75 & 73 & 74 \\
\hline$(\mathrm{mmHg})$ & SD & 12 & 11 & 10 & 9 & 8 & 8 & 10 \\
\hline $\mathrm{VO}_{2} \max$ & $\bar{x}$ & 35.0 & 38.9 & 40.6 & 43.2 & 47.8 & 48.4 & 59.2 \\
\hline \multirow[t]{2}{*}{$\left(\mathrm{ml}, \mathrm{kg}^{-1} \mathrm{~min}^{-1}\right)$} & SD & 4.9 & 6.1 & 6.5 & 7.6 & 10.3 & 8.8 & 5.4 \\
\hline & $\mathbf{n}$ & 100 & 89 & 105 & 95 & 55 & 30 & 25 \\
\hline
\end{tabular}

remaining $78 \%$ did not. Since the subjects were all volunteers it is likely that the number of individuals in the general population doing this minimum amount of exercise will be less than the $22 \%$ found in this sample.

The activity patterns of the older subjects were different from those of the younger subjects (Fig. 3). The percentage of sedentary individuals increased in the older age groups whereas the number of "moderately active" individuals i.e. those who exercised on a regular basis 1-2 times a week decreased. However the number of subjects exercising regularly three or more times a week did not vary from one age group to the next. This suggests that those individuals who develop an active lifestyle in early adulthood (20-30 years) are unlikely to lose their exercise habit as they get older. On the other hand those who only take exercise 1-2 times a week are in danger of slipping into a sedentary way of life as they get older. This pattern will be examined further when the remaining 3,500 subjects are investigated. This pattern with age may be influenced by the voluntary nature of the test which is likely to attract the more active element of the population and this may be particularly so in the older age groups.

The activity level of this sample is greater than that reported by Tuxworth and co-workers for a group of British factory workers (Tuxworth et al, 1986). Although the number of sedentary individuals was slightly greater in this sample (38\% compared with $33 \%$ in the factory workers) the number performing strenuous activity at least once a week was much greater (61 per cent compared with 28 per cent in the factory group). This difference may be related to differences in social class, education or income levels. This evidence further supports the above suggestion that the number of people in the British population performing the required amount of exercise for cardiovascular benefit is likely to be less than the 22 per cent found in this sample.

In the Canadian Lifestyle Study, Jette reported that $11 \%$ of the population were sedentary and fifty-six per cent were active i.e. exercised for more than three hours a week. The activity level of this group was probably less, i.e. $39 \%$ were sedentary and only $5 \%$ exercised for more than three hours each week. However, the different ways of classifying activity means that such comparisons cannot be taken too literally.

Although the activity patterns of this sample have been compared with others, the different ways of classifying activity makes direct comparisons difficult. The activity classification adopted in this study is more detailed than many and includes questions about the type, intensity, frequency and duration of the exercise taken. These areas were assessed because these factors are all considered to be important if increased functional capacity is required. However the exercise required to do this may not be the same as the exercise required to enhance health. Kavanagh (1982) demonstrated in a group of patients with coronary artery insufficiency that provided they performed a minimum amount of exercise each week the intensity of that exercise was not critical for elevating the high density lipoprotein cholesterol level.

\section{Physical activity and age in relation to fitness and health}

Physical activity levels, independent of age, influenced a number of the health-related parameters measured in this study. Resting arterial blood pressure, resting pulse rate, body weight and body fat percentage all progressively decreased with increasing levels of activity (Tables II and IV) and predicted maximal oxygen uptake increased. In contrast, blood pressure, pulse rate, body weight and body fat were all higher in the older age groups and maximum oxygen uptake was lower than in the younger age groups.

These findings are consistent with the evidence that increasing age results in a deterioration of functional capacity and health, whereas regular exercise results in beneficial health changes and an increase in functional capacity. However it is possible that these health-related values may have been influenced by selection as the heavier, fatter individuals are less likely to pursue an active lifestyle and to attend for fitness assessment.

\section{Predicted maximal oxygen uptake $\left(\mathrm{ml}^{\mathrm{kgg}} \mathbf{~}^{-1} \mathrm{~min}^{-1}\right)$}

The average predicted $\nabla_{2}$ for this group was $41.9 \pm 9.0$ $\mathrm{ml} \mathrm{kg}^{-1} \mathrm{~min}^{-1}$. This value compares favourably with that reported by Jetté in his Canadian study but is generally higher than other values for British men (Tuxworth et al, 1986). It is higher than the mean $\mathrm{VO}_{2}$ max value of $36.8 \pm$ $8.2 \mathrm{ml}^{.} \mathrm{kg}^{-1} \mathrm{~min}^{-1}$ found in a group of 600 British computer employees with an average age of 32 years (BUPA unpublished data, 1987). However, the mean value for the sedentary section of the group under study was $35.0 \pm$ $4.9 \mathrm{ml} . \mathrm{kg}^{-1} \mathrm{~min}^{-1}$ and this is consistent with those reported in the literature for untrained middle-aged European men (Masironi and Denolin, 1985). This suggests that the group under investigation was more active than other British groups studied and this is reflected in the higher average $\mathrm{VO}_{2}$ max value. It is possible that this group are more activity conscious than other groups of the population because they are higher paid, better educated and more informed. Despite this the numbers performing adequate exercise are small (22\%) and the number under-exercising or not exercising at all are large.

The factors which may have contributed to the higher $\mathrm{VO}_{2}$ max values found in this study when compared with other studies on British men may be summarised as follows:

\section{Methodology -}

(a) the use of uphill treadmill exercise produces values that are higher by $4-8 \%$ and $3 \%$ than cycling and steptesting respectively (Åstrand and Rodahl, 1977).

(b) the maximal heart rate formula used $(220-($ age $\times 0.65)$ ) gives higher estimates of maximum heart rate than some other methods. 


\section{Sample -}

(a) voluntary attendance is likely to attract naturally "fitter" people in terms of cardiovascular capacity and/or more active people.

(b) the majority of the sample came from social classes $A$ and $B$. The income and education of these groups may influence their activity levels when compared with other social classes.

When comparing fitness parameters of one population with those of another attention must be given to both the methodology and the sample selection.

\section{CONCLUSION}

The voluntary attendance of the subjects for fitness assessment probably attracted the fitter and more active members of the population with greater functional capacity. This is reflected in the maximal oxygen uptake values which are higher than those published in other studies of British men.

Despite the fact that the subjects in the present study were probably more active than in the population at large, only 22 per cent carried out the necessary exercise required to maintain a good functional capacity.

The analysis of the activity patterns of the different age groups suggested that those individuals who are only moderately active in early adulthood (20-30 years) are likely to lose their exercise habit as they get older. On the other hand those who exercise regularly three or more times a week are not likely to lose their exercise habit as they get older.

The older and less active individuals had lower functional capacities and were less healthy than the younger and more active groups. This is consistent with the evidence that age leads to a deterioration in health and functional capacity whereas exercise benefits these characteristics. This supports the current recommendations for maintaining good health through an active lifestyle.

\section{References}

American College of Sports Medicine, 1979 "The recommended quantity and quality of exercise for developing and maintaining fitness in healthy young adults". Med.Sci.Sports 10, vii-ix.

American College of Sports Medicine, 1986. Guidelines for Exercise Testing and Prescription, Third Edition.

American Heart Association, 1972. Exercise Testing and Training of Healthy Individuals: A Handbook for Physicians".

Astrand, P.-O., 1956 "Human physical fitness with special reference to sex and age". Physiol.Rev. 36: 307-329.

Astrand, P.-O. and Rodahl, K., 1977. Textbook of Work Physiology. McGraw Hill.

Astrand, I., 1960 "Aerobic working capacity in men and women with special reference to age". Acta Med.Scand. 49, Suppl. 169.

Canadian Fitness Survey, 1983. Fitness and Lifestyle in Canada. Ottawa: Govt. of Canada.

Cohen, L. and Holliday, M., 1979. Statistics for Education and Physical Education. Harper and Row, London.

Durnin, J. and Womersley, J., 1974 "Body fat assessed from total body density and its estimation from skinfold thickness: measurement on $\mathbf{4 8 1}$ men and women aged 16 to 72 years". Br.J.Nutr. 32: 77-85.

Henley Centre for Forecasting, 1986. Sports and Coumtryside Activity in the UK. London: The Sports Council, in press.

Hodgson, G, 1986. Market Segmentation: An Analysis of Patients Attending the BUPA Fitness Assessment Unit, London. MSc Thesis. (Loughborough University, England).

Jakeman, P. and Davies, B., 1979 "The characteristics of a low resistance breathing valve designed for the measurement of high aerobic capacity". Brit.J.Sports Med. 13: 81-83.

Jetté, M., 1978 "The standardised test of fitness in occupational health". Can.J.Public Health 69, Nov/Dec: 431-438.

Kavanagh, T., Shephard, R. and Tuck, J., 1983 "Influence of exercise and lifestyle variables upon HDL cholesterol following myocardial infarction". Arteriosclerosis 3: 249-259.

Maritz, J., Morrison, J., Peter, J., Strydom and Wyndam, C., 1961 "A practical method of estimating an individual's maximal oxygen intake". Ergonomics 4: 97-101

Masironi, R. and Denolin, H., 1985. Physical Activity in Disease: Prevention and Treatment.

Paffenbarger, R. S., Wing, A. L. and Hyde, R. T., 1978 "Physical activity as an index of heart attack risk in college alumuni". Amer.J.Epidemiol. 108: 161-75.

Taylor, H., Buskirk, E. and Henschel, A., 1955 "Maximal oxygen intake as an objective measure of cardiorespiratory performance". J.Appl.Physiol. 8: 73-80.

Tuxworth, W., Nevill, A., White, C. and Jenkins, C., 1986 "Health, fitness, physical activity, and morbidity of middle-aged male factory workers 1 ". Brit.J.Indust.Med. 43: 733-753.

Williams, D. and Hamley, E., 1986 “Training responses of two age groups during treadmill walking". Brit.J.Sports Med. 20 (1): 10-13.

Williams, D. and Williams, C., 1983 “Cardiovascular and metabolic responses of trained and untrained middle-aged men to a graded treadmill walking test". Brit.J.Sports Med. 17 (1): 110-116. 